\title{
MOLECULAR MECHANISMS UNDERLYING CANCER CELL RADIORESISTANCE
}

\author{
Inna Chorna \\ Ph.D., Assistant Professor, Sumy State University, Ukraine \\ e-mail: i.chorna@med.sumdu.edu.ua, orcid.org/0000-0002-3094-4518
}

\section{Summary}

Radioresistance of the tumor cells remains a significant obstacle for the radiotherapy treatment of cancer. Radioresistance involves multiple genes, factors, and mechanisms that adapt cancer cells or tissues to radiotherapy-induced changes and develop resistance to ionizing radiation. The major studies of the effect of radiation on cells reported include the following areas: 1) the study of DNA damages and their repair; 2) mutations in tumor suppressor genes and radiation-induced oncogene expression; 3) the role of growth factors and cytokines; 4) violation of the cell cycle; 5) elucidation of the mechanisms of apoptosis and necrosis.

This review aimed to provide a theoretical basis, which may improve the sensitivity of cancer cells to radiotherapy. It focuses on the roles of tumor metabolism, DNA repair capacity, cell cycle checkpoints, and the tumor microenvironment in the development of radioresistance of cancer cells. Understanding the molecular alterations that lead to radioresistance may provide new diagnostic markers and therapeutic targets to improve radiotherapy efficacy.

Keywords: ionizing radiation, DNA repair, cell cycle, proliferation, radiotherapy.

\section{DOI: https://doi.org/10.23856/4818}

\section{Introduction}

According to the latest studies, the main factors involved in the development of radioresistance are the following: 1) DNA damage repair; 2) cell cycle arrest; 3) oncogene and tumor suppressor alterations; 4) changes in the tumor microenvironment; 5) autophagy (a proteasome-independent degradation of cellular components); 6) the generation of cancer stem cells (undifferentiated cancer cells with high oncogenic activity, with the self-renewal ability and multi-directional differentiation potential); 7) tumor metabolism alterations (Chen et al., 2017; Fengsheng et al., 2016; Tang et al., 2018; Yoshida et al., 2016; Zhang et al., 2016).

Ionizing radiation induces a number of DNA damage, including single-strand breaks (SSB) and double-strand breaks (DSB), damage of nitrogenous bases and sugar residues, the formation of inter-strand and intra-strand crosslinks of DNA-DNA and DNA-protein, the appearance of chromosomal aberrations (Liu et al., 2021). Radiotherapy directly induces DNA damage or indirectly causes oxidative stress. Free hydroxyl radicals are considered the ionizing radiation-induced mediators of DNA damage, including SSB and DSB, which disturb the DNA structure, triggering cell death (Tang et al., 2018). Like most normal cells, tumor cells have reparative systems capable of repairing damage and restoring the native structure of DNA through specific mechanisms and enzymatic complexes. DNA damage may be recognized by detectors specific to different types of repair.

Moreover, additional detector proteins are involved in the regulation of the cell cycle and are involved in the arrest or slowing of the cell cycle in the presence of DNA damage at various stages of the cell cycle. Here, an overview is provided to elucidate the interplay between tumor cell metabolism, DNA repair ability, microenvironment, and radioresistance. 


\section{Cell cycle redistribution in irradiated cells}

Initial biological responses to radiation damage occur at the molecular, cellular, subcellular levels and at intervals ranging from seconds to hours or days. Among the many manifestations of the effect of ionizing radiation on cell viability, the most important is replicative cell death (suppression of the ability to divide).

The second type of replicative death of irradiated cells is the formation of so-called giant cells, which arise from the fusion of two neighboring, often "sister" cells. Such cells are capable of no more than 2-3 divisions, after which they die. Giant cells can form without fusion with a long delay in cell division of irradiated cells or their offspring. This method of cell death is inherent in aging cells and is observed after exposure to ionizing radiation. It is known that the sensitivity to radiation may also depend on the rate of proliferation of target cells (Erenpreisa et al., 2001; Suzuki et al., 2001).

As a result of DNA damage, cell growth may stop (Sia et al., 2020). At the heart of the events leading to cycle arrest in the G1 phase are reactions that increase the level of p53 protein, which, as a transcription factor, activates genes involved in cell cycle blockade (p21), induction of apoptosis (Bax), and repair (Gadd45). Ionizing radiation-induced ATM-dependent serine phosphorylation was found in p53 protein (Khanna et al., 1998). In addition, Chk2-catalyzed phosphorylation of serine 20 (Chechab et al., 2000) is also necessary for p53 stabilization, which inhibits p53 binding to MDM2. Chk2 kinase is activated by ATM (Ward et al., 2001), and thus, directly and indirectly, ATM is involved in p53 stabilizing by phosphorylation. Also, by phosphorylation of serine 395 in the MDM2 protein, ATM influences the ability of MDM2 to bind p53 (Khosravi et al., 1999). The final result of phosphorylation is the destabilization of p53-MDM2 binding, stabilization of p53 protein, and its activation as a transcription factor, which allows blocking the cell cycle in the G1 phase.

$\mathrm{p} 21$, an inhibitor of cyclin-dependent Cdk2 kinases, plays a fundamental role in blocking the cell cycle in the $\mathrm{G} 1$ phase. Inhibition of $\mathrm{Cdk} 2 /$ cyclin $\mathrm{E}$ kinases prevents phosphorylation of the $\mathrm{Rb}$ (Retinoblastoma) protein and the release of the transcription factor E2F. It blocks the transcription of many proteins needed to initiate DNA synthesis, thereby blocking the cell cycle at the G1 stage. In addition to induction of $\mathrm{p} 21$, the $\mathrm{p} 53$ protein also activates the transcription of other regulatory proteins: the 14-3-3 protein, responsible, among other things, for the removal of Cdc 2 kinase from the nucleus, and the Gadd 45 protein, which, apart from participating in the repair of DNA damage, also regulates the activity of Cdc2 kinase (Al Bitar et al., 2019). It was found that the different members of the 14-3-3 family of proteins could control p53 activity, and

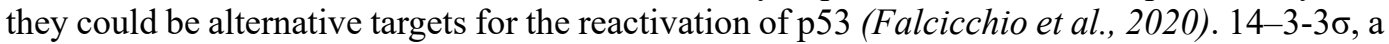
member of the 14-3-3 protein family, was closely associated with the radioresistance development by arresting cancer cells in the G2/M phase (Chen et al., 2017).

Mammalian cells exposed to ionizing radiation can be blocked in the G2/M phase by inactivating and translocating the protein phosphatase $\mathrm{Cdc} 25 \mathrm{C}$, an activator of CDK kinases, resulting from its phosphorylation (serine 216) by Chk2 kinase (O'Connell et al., 2000). Chk2 activation requires the presence of ATM and Nbs1 (Buscemi et al., 2001). It is impaired in AT (Ataxia-Telangiectasia) cells and in cells with inactive Nbs1 protein that is also defective at the G2/M checkpoint. The association of ATM with BRCA1 and the phosphorylation of BRCA1 by ATM increases under the influence of ionizing radiation (Gatei et al., 2000) and contributes to cell cycle arrest in the G2 phase.

The arrest of cells in the G1 phase under ionizing radiation occurs due to the transactivation of $\mathrm{p} 21 \mathrm{CIP} / \mathrm{WAF} 1$ by the $\mathrm{p} 53$ protein. $\mathrm{p} 21 \mathrm{CIP} / \mathrm{WAF} 1$ protein, in turn, inhibits 
cyclin-dependent kinases and prevents the transition of cells to the $\mathrm{S}$ phase of the cell cycle, thus allowing DNA repair. (Al Bitar et al., 2019; Morgan et al., 2015; Shu et al., 2007).

Cell arrest in the G1 phase of the cell cycle in response to ionizing radiation can also occur via the p53-independent signaling pathway. Thus, activated ATM kinase phosphorylates and activates c-ABL kinase, which, in turn, can activate p73, leading to transactivation of $\mathrm{p} 21$ and GADD45 (Dasika et al., 1999; Lee et al., 1999).

Irradiation of cells causes a slowdown in the $\mathrm{S}$ phase of the cell cycle. ATM, NBS1, CHK2, Cdc25A, BRCA1, SMC1, MRE11, and others are involved in this process (Falck et al., 2002; Kastan et al., 2001). It has been reported that BRCA1 phosphorylation by ATM kinase is necessary for the radiation-induced arrest of cells in the $\mathrm{S}$ phase of the cell cycle $(X u$ et al., 2002).

Considering all the above, we can say that stopping cell growth due to exposure to ionizing radiation is also associated with either DNA repair or the apoptosis process required to eliminate cells that can't repair damaged DNA.

\section{DNA damage and repair in irradiated cells}

A signaling cascade is triggered in response to DNA damage, consisting of sensory, transducer, and effector proteins, which can stop cell growth, repair DNA or, trigger cell death (apoptosis). Sensory proteins (RAD9, RAD1, RAD17, HUS1, and others) recognize DNA damage and are likely to respond to it by directly linking double-stranded DNA breaks in mammalian cells. The RAD17 protein promotes the recognition of DNA damage by the RAD1-RAD9-HUS1 complex. ATM/ATR kinase phosphorylates the effector kinases CHK1 and CHK2, which phosphorylate the p53 protein on the Ser20 residue and other target proteins in mammalian cells (Liu et al., 2021). A model was proposed, according to which changes in the structure of chromatin after DNA damage may contribute to the rapid activation of ATM kinase (Bakkenist et al., 2003).

It has been reported that histone $\mathrm{H} 2 \mathrm{AX}$ phosphorylation occurs at the sites of double-stranded DNA breaks with the participation of ATM kinase. H2AX is involved in creating specific DNA-repair complexes on damaged DNA (Sharma et al., 2012). At the same time, p53 and the MDM2 protein, which mediates the degradation of $\mathrm{p} 53$, are phosphorylated directly by ATM kinase on Ser15 and Ser395 residues, respectively (Maya et al., 2001). The phosphorylation sites of p53 (Ser15 and Ser20) and MDM2 (Ser395) are localized in the region of interaction of these proteins with each other. Thus, phosphorylation disrupts the binding of MDM2 to p53 and thus protects the p53 protein from ubiquitination and degradation (Marine et al., 2010). It has been discovered that in the offsprings of human fibrosarcoma cells of the HT1080 line, survived after exposure to X-ray irradiation at a dose of $6 \mathrm{~Gy}$, slow down of the activation of p53 protein occurs (Suzuki et al., 2003).

Cells have many mechanisms that enable them to survive under genotoxic stress. The most important of these is the repair of DNA damage and blockage of the cell cycle. Restoration of a variety of DNA damage is possible thanks to the development of specialized repair systems, each of which is responsible for removing specific types of damage. Depending on the type of DNA damage, there are several main mechanisms of repair. Excision repair of nitrogenous bases is necessary to correct modified bases formed by the action of free radicals on DNA. This type of violation occurs by indirect damage of DNA by ionizing radiation. There are several stages of excision repair. In the first stage, the damaged nitrogenous base is cleaved by DNA glycosylases, which hydrolyze the N-glycosidic bond between the damaged base and the deoxyribose residue. Deoxyribose without a nitrogenous base, the so-called apurinic/apyrimidinic 
site (AP site), is excised by AP endonucleases. In the second stage, the formed "gap", which has the size of one base, is repaired to the original sequence by the combined action of exonucleases, polymerase, and DNA ligase. Repair of single-stranded DNA breaks occurs using a complementary DNA strand as a template (Jasin et al., 2013; Marsden et al., 2017). The protein poly-ADP-ribose polymerase (PARP) plays an essential role in the initiation of enzymes of excision repair. Even before the activation of repair enzymes, PARP binds to the rupture of DNA and prevents the destruction of free end regions of DNA. In addition, PARP, along with DNA-dependent protein kinase (DNA-PC) and ATM protein, is involved in providing a delay in the cell cycle, which is necessary to complete the repair process (Javle et al., 2011).

Single strand breaks (SSB) may arise via direct radiation-induced DNA damage or as intermediaries formed during the repair of other single strand lesions (e.g., base excision repair of oxidized bases) (Morgan et al., 2015).

Double strand breaks (DSB) are the most dangerous type of DNA damage for a cell. They lead to the development of mutations and chromosomal rearrangements (aberrations), cell death, and the formation of genetic instability (Vitor et al., 2020). In eukaryotic organisms, two main mechanisms of repair double-strand DNA breaks have been identified: homologous recombination (HR) and non-homologous end-joining (NHEJ). In the HR, using the undamaged homologous DNA fragment as a template with a sequence complementary to at least one broken end occurs, whereas NHEJ does not require a homologous template (Brandsma et al., 2012; Frankenberg-Schwager et al., 2009; Mao et al., 2008).

The complex of proteins involved in double-stranded DNA breaks repairing by the HR mechanism includes ATM, BLM, BRCA1/2, c-ABL, RAD51/51C/51D/52/54, XRCC2/3, and others. Extensive studies have reported that radioresistance of hypoxic cancer cells is induced by the ATM-dependent DNA damage repair pathway, mainly through upregulation of HR mechanism of repair (Bencokova et al., 2009; Hashimoto et al., 2018; Olcina et al., 2014). In response to DNA strand breaks, the activated form of ATM phosphorylates some HR-related factors, such as BRCA1 and FANCD2, triggering the DNA damage repair pathway. It has been suggested that ATM also plays a pivotal role in the radioresistance of cancer cells under hypoxic conditions (Suwa et al., 2021).

A non-homologous joining occurs between ends of DNA that have non-homologous sequences or very short homologous regions. This reparation is not infallible and is often a source of genetic rearrangements (Mladenov et al., 2011; Morgan et al., 2015). Restoration of the original structure of DNA is possible only if the joining between the ends of the same strand of DNA occurs. If a process occurs between different molecules, it causes chromosomal aberrations, such as deletions, insertions, translocations, and inversions. NHEJ mechanism is carried out by a complex of proteins, including DNA-dependent protein kinase (DNA-PK), Ku70, Ku86, DNA ligase IV, XRCC4, and others. In addition, proteins MRE11, RAD50, and NBS1 (MRN complex) are involved in DNA damage repair by both the mechanism of HR and NHEJ (Her et al., 2018; Morgan et al., 2015). Tumor suppressors p53 and BRCA1 control the course of HR and NHEJ, but their effect on radioresistance remains the subject of intensive research (Gorodetska et al., 2019; Moureau et al., 2016).

The inability of cells to repair double-stranded gaps leads to genome destabilization and tumors. In some cases, double-stranded DNA breaks contribute to the induction of apoptosis. Some researchers attribute the resistance of many cells to radiation to the kinetics and repair efficiency of single- and double-stranded DNA breaks, which can also serve as an additional method of monitoring the radiotherapeutic response in the clinic (Huang et al., 2020; Velegzhaninov et al., 2020). 


\section{Tumor metabolism alterations in irradiated cells}

Cancer cells can obtain sufficient oxygen only when they are localized close to tumor blood vessels. On the other hand, cancer cells far from functional blood vessels can get the minimal oxygen level necessary for their survival but insufficient for active proliferation (Suwa et al., 2021). Cancer cells in hypoxic regions produce ATP energy mainly via anaerobic glycolysis and generate lactate as a byproduct, leading to a unique microenvironment formation with a low $\mathrm{pH}$. On the other hand, cancer cells farther away from blood vessels are deprived of oxygen and nutrients, and they die because of necrosis (Harada, 2011; Yeom et al., 2012). Cancer cells adapt to hypoxic conditions by inducing the expression of hypoxia-inducible factor 1 (HIF-1), which causes the expression of various pro-angiogenic factors, such as vascular endothelial growth factor (VEGF) and platelet-derived growth factor (PDGF). Besides, HIF-1 mediates the activation of the pentose phosphate pathway (PPP) (Meijer et al., 2012). The PPP, whose initial metabolite glucose-6-phosphate, is supplied via glycolysis, generates pentose sugars and ribose-5-phosphate and generates NADPH as a byproduct (Patra et al., 2014). Because NADPH is a coenzyme of an antioxidant enzyme glutathione reductase, which converts oxidized glutathione (GSSG) into reduced form (GSH), and ribose-5-phosphate is essential for nucleotide synthesis, so HIF-1-mediated activation of the PPP is associated with the radioresistance of hypoxic cancer cells (Harada, 2016; Nakashima et al., 2017; Telarovic et al., 2021).

Glucose transporter 1 (GLUT1) protein is involved in the glucose transport through the cellular membrane into the cell, and it is upregulated under hypoxic conditions (Chung et al., 2009). GLUT1 overexpression was reported to be associated with radioresistance and poor prognosis in patients with oral squamous cell carcinoma and head and neck squamous cell carcinoma (De Schutter et al., 2005; Kunkel et al., 2007). Radioresistant tumor cells often have high levels of GLUT1, which was associated with oncogene activation, tumor suppressor inactivation, hypoxia stimulation, and the regulation of different signaling pathways, such as MAPK and PI3K/AKT (Fang et al., 2015).

The elevated glycolysis rate facilitates the rejoining of radiation-induced DNA strand breaks by activating NHEJ and HR repair mechanisms, thus reducing the radiation-induced cytogenetic damage in cancer cells (Bhatt et al., 2015).

\section{Tumor microenvironment and radioresistance of cancer cells}

Malignant tumor tissues consist of cancer cells and a wide variety of other cells responsible for the inflammatory response, angiogenesis, immune response, and support of the tumor tissue architecture, forming a complex cellular society (Suwa et al., 2021). Many immunosuppressive processes increase the risk of tumor recurrence and metastasis, and immune evasion has emerged as a severe obstacle in cancer treatment (Tang et al., 2017). Changes in the cytokine levels, epithelial-mesenchymal transition (EMT)-related processes, and hypoxic conditions can promote radioresistance in tumor cells (Goffart et al., 2017; Krisnawan et al., 2020; Zhang et al., 2016).

Recent studies have shown that tumor-associated macrophages (TAMs), which exist abundantly in tumor tissues, promote tumor growth and enhance radioresistance in various cancers (Brown et al., 2017; Dehne et al., 2017). TAMs induce the expression of cyclooxygenase-2 (COX-2) - an enzyme participating in the synthesis of prostaglandin E2 (PGE2) which has been reported to accelerate tumor growth and induce radioresistance in cancers (Cook et al., 2016). In addition, it has been suggested that TAMs induce high expression of tumor necrosis factor- $\alpha$ 
(TNF- $\alpha$ ), promote angiogenesis, and facilitate tumor recurrence after radiotherapy (Meng et al., 2010). Vascular endothelial growth factor (VEGF) and platelet-derived growth factor (PDGF), secreted from M2-type macrophages, promote tumor regrowth after radiotherapy (Balkwill et al., 2001). It has been reported that some factors secreted from cancer-associated fibroblasts (CAFs) induce radioresistance in cancer cells. For example, CAFs secrete epidermal growth factor (EGF), insulin-like growth factor 2 (IGF2), and fibroblast growth factor 4 (FGF4), which increase both the proliferation and the survival of cancer cells after irradiation (Chu et al., 2014; Krisnawan et al., 2020). Besides, stromal cell-derived factor 1 (SDF-1) and $\beta$-hydroxybutyrate secreted from CAFs induce autophagy in irradiated cancer cells and accelerate the regrowth of tumors (Wang et al., 2017).

In addition, non-irradiated cells may receive apoptotic signals from neighboring irradiated cells through the bystander effect, inducing the non-irradiated cells to exhibit similar biological effects to those of the irradiated cells (Chevalier et al., 2015).

\section{Conclusions}

Radioresistance of cancer cells can be provided by more than one mechanism. Radiotherapy may induce alterations in many molecules and signaling pathways involved in the tumor cell metabolism, and radiation-induced metabolic changes in cancer cells may affect the efficacy of radiotherapy. Cancer cells undergo a range of interphase and mitotic death after irradiation via direct and indirect effects of ionizing radiation. Although most radiation-induced DNA breaks in cancer cells are rapidly repaired, residual breaks or erroneous DNA repair lead to genetic instability, increased mutation rates, and chromosomal aberrations. An increased understanding of the molecular mechanisms of radiation-induced cell death will reveal novel opportunities for improving the overall anti-tumor efficacy of radiation therapy.

\section{References}

Al Bitar, S., \& Gali-Muhtasib, H. (2019). The Role of the Cyclin Dependent Kinase Inhibitor p21cip1/waf1 in Targeting Cancer: Molecular Mechanisms and Novel Therapeutics. Cancers, 11(10), 1475. https://doi.org/10.3390/cancers11101475

Bakkenist, C. J., \& Kastan, M. B. (2003). DNA damage activates ATM through intermolecular autophosphorylation and dimer dissociation. Nature, 421(6922), 499-506. https://doi. org/10.1038/nature01368

Balkwill, F., \& Mantovani, A. (2001). Inflammation and cancer: back to Virchow?. Lancet (London, England), 357(9255), 539-545. https://doi.org/10.1016/S0140-6736(00)04046-0

Bencokova, Z., Kaufmann, M. R., Pires, I. M., Lecane, P. S., Giaccia, A. J., \& Hammond, E. M. (2009). ATM activation and signaling under hypoxic conditions. Molecular and cellular biology, 29(2), 526-537. https://doi.org/10.1128/MCB.01301-08

Bhatt, A. N., Chauhan, A., Khanna, S., Rai, Y., Singh, S., Soni, R., Kalra, N., \& Dwarakanath, B. S. (2015). Transient elevation of glycolysis confers radio-resistance by facilitating DNA repair in cells. BMC cancer, 15, 335. https://doi.org/10.1186/s12885-015-1368-9

Brandsma, I., \& Gent, D. C. (2012). Pathway choice in DNA double strand break repair: observations of a balancing act. Genome integrity, 3(1), 9. https://doi.org/10.1186/2041-9414-3-9 Brown, J. M., Recht, L., \& Strober, S. (2017). The Promise of Targeting Macrophages in Cancer Therapy. Clinical cancer research : an official journal of the American Association for Cancer Research, 23(13), 3241-3250. https://doi.org/10.1158/1078-0432.CCR-16-3122 
Buscemi, G., Savio, C., Zannini, L., Miccichè, F., Masnada, D., Nakanishi, M., Tauchi, H., Komatsu, K., Mizutani, S., Khanna, K., Chen, P., Concannon, P., Chessa, L., \& Delia, D. (2001). Chk2 activation dependence on Nbs1 after DNA damage. Molecular and cellular biology, 21(15), 5214-5222. https://doi.org/10.1128/MCB.21.15.5214-5222.2001

Chehab, N. H., Malikzay, A., Appel, M., \& Halazonetis, T. D. (2000). Chk2/hCds1 functions as a DNA damage checkpoint in G(1) by stabilizing p53. Genes \& development, 14(3), 278-288.

Chen, Y., Li, Z., Dong, Z., Beebe, J., Yang, K., Fu, L., \& Zhang, J. T. (2017). 14-3-36 Contributes to Radioresistance By Regulating DNA Repair and Cell Cycle via PARP1 and CHK2. Molecular cancer research : MCR, 15(4), 418-428. https://doi.org/10.1158/1541-7786.MCR-16-0366 Chevalier, F., Hamdi, D. H., Saintigny, Y., \& Lefaix, J. L. (2015). Proteomic overview and perspectives of the radiation-induced bystander effects. Mutation research. Reviews in mutation research, 763, 280-293. https://doi.org/10.1016/j.mrrev.2014.11.008

Chu, T. Y., Yang, J. T., Huang, T. H., \& Liu, H. W. (2014). Crosstalk with cancer-associated fibroblasts increases the growth and radiation survival of cervical cancer cells. Radiation research, 181(5), 540-547. https://doi.org/10.1667/RR13583.1

Chung, F. Y., Huang, M. Y., Yeh, C. S., Chang, H. J., Cheng, T. L., Yen, L. C., Wang, J. Y. \& Lin, S. R. (2009). GLUT1 gene is a potential hypoxic marker in colorectal cancer patients. BMC Cancer, 9, 241. https://doi.org/10.1186/1471-2407-9-241

Cook, P. J., Thomas, R., Kingsley, P. J., Shimizu, F., Montrose, D. C., Marnett, L. J., Tabar, V. S., Dannenberg, A. J., \& Benezra, R. (2016). Cox-2-derived PGE2 induces Id1-dependent radiation resistance and self-renewal in experimental glioblastoma. Neuro-oncology, 18(10), 1379-1389. https://doi.org/10.1093/neuonc/now049

Dasika, G. K., Lin, S. C., Zhao, S., Sung, P., Tomkinson, A., \& Lee, E. Y. (1999). DNA damage-induced cell cycle checkpoints and DNA strand break repair in development and tumorigenesis. Oncogene, 18(55), 7883-7899. https://doi.org/10.1038/sj.onc.1203283

De Schutter, H., Landuyt, W., Verbeken, E., Goethals, L., Hermans, R., \& Nuyts, S. (2005). The prognostic value of the hypoxia markers CA IX and GLUT 1 and the cytokines VEGF and IL 6 in head and neck squamous cell carcinoma treated by radiotherapy +/- chemotherapy. BMC cancer, 5, 42. https://doi.org/10.1186/1471-2407-5-42

Dehne, N., Mora, J., Namgaladze, D., Weigert, A., \& Brüne, B. (2017). Cancer cell and macrophage cross-talk in the tumor microenvironment. Current opinion in pharmacology, 35, 12-19. https://doi.org/10.1016/j.coph.2017.04.007

Erenpreisa, J., Cragg, M. S. (2001). Mitotic death: a mechanism of survival? A review. Cancer Cell International, 1(1), 1-7. https://doi.org/10.1186/1475-2867-1-1

Falcicchio, M., Ward, J. A., Macip, S. \& Doveston, R. G. (2020). Regulation of p53 by the 14-3-3 protein interaction network: new opportunities for drug discovery in cancer. Cell Death Discovery, 6, 126. https://doi.org/10.1038/s41420-020-00362-3

Falck, J., Petrini, J. H., Williams, B. R., Lukas, J., \& Bartek, J. (2002). The DNA damage-dependent intra-S phase checkpoint is regulated by parallel pathways. Nature genetics, 30(3), 290-294. https://doi.org/10.1038/ng845

Fang, J., Zhou, S. H., Fan, J., \& Yan, S. X. (2015). Roles of glucose transporter-1 and the phosphatidylinositol 3-kinase/protein kinase B pathway in cancer radioresistance (review). Molecular medicine reports, 11(3), 1573-1581. https://doi.org/10.3892/mmr.2014.2888

Frankenberg-Schwager, M., Gebauer, A., Koppe, C., Wolf, H., Pralle, E., \& Frankenberg, D. (2009). Single-strand annealing, conservative homologous recombination, nonhomologous DNA end joining, and the cell cycle-dependent repair of DNA double-strand breaks induced by sparsely or densely ionizing radiation. Radiation research, 171(3), 265-273. https://doi. org/10.1667/RR0784.1 
Gatei, M., Scott, S. P., Filippovitch, I., Soronika, N., Lavin, M. F., Weber, B., \& Khanna, K. K. (2000). Role for ATM in DNA damage-induced phosphorylation of BRCA1. Cancer research, 60(12), 3299-3304.

Goffart, N., Lombard, A., Lallemand, F., Kroonen, J., Nassen, J., Di Valentin, E., Berendsen, S., Dedobbeleer, M., Willems, E., Robe, P., Bours, V., Martin, D., Martinive, P., Maquet, P., \& Rogister, B. (2017). CXCL12 mediates glioblastoma resistance to radiotherapy in the subventricular zone. Neuro-oncology, 19(1), 66-77. https://doi.org/10.1093/neuonc/now136

Gorodetska, I., Kozeretska, I., \& Dubrovska, A. (2019). BRCA Genes: The Role in Genome Stability, Cancer Stemness and Therapy Resistance. Journal of Cancer, 10(9), 2109-2127. https://doi.org/10.7150/jca.30410

Harada H. (2011). How can we overcome tumor hypoxia in radiation therapy?. Journal of radiation research, 52(5), 545-556. https://doi.org/10.1269/jrr.11056

Harada H. (2016). Hypoxia-inducible factor 1-mediated characteristic features of cancer cells for tumor radioresistance. Journal of radiation research, 57 Suppl 1(Suppl 1), i99-i105. https://doi.org/10.1093/jrr/rrw012

Hashimoto, T., Murata, Y., Urushihara, Y., Shiga, S., Takeda, K., \& Hosoi, Y. (2018). Severe hypoxia increases expression of ATM and DNA-PKcs and it increases their activities through Src and AMPK signaling pathways. Biochemical and biophysical research communications, 505(1), 13-19. https://doi.org/10.1016/j.bbrc.2018.09.068

Her, J., \& Bunting, S. F. (2018). How cells ensure correct repair of DNA double-strand breaks. The Journal of biological chemistry, 293(27), 10502-10511. https://doi.org/10.1074/jbc.TM118.000371 Huang, R. X., Zhou, P. K. (2020). DNA damage response signaling pathways and targets for radiotherapy sensitization in cancer. Signal Transduction and Targeted Therapy, 5, 60. https://doi.org/10.1038/s41392-020-0150-x

Jasin, M., \& Rothstein, R. (2013). Repair of strand breaks by homologous recombination. Cold Spring Harbor perspectives in biology, 5(11), a012740. https://doi.org/10.1101/cshperspect. a012740

Javle, M., \& Curtin, N. J. (2011). The role of PARP in DNA repair and its therapeutic exploitation. British journal of cancer, 105(8), 1114-1122. https://doi.org/10.1038/bjc.2011.382

Kastan, M. B., Lim, D. S., Kim, S. T., \& Yang, D. (2001). ATM--a key determinant of multiple cellular responses to irradiation. Acta oncologica (Stockholm, Sweden), 40(6), 686-688. https://doi.org/10.1080/02841860152619089

Khanna, K. K., Keating, K. E., Kozlov, S., Scott, S., Gatei, M., Hobson, K., Taya, Y., Gabrielli, B., Chan, D., Lees-Miller, S. P., \& Lavin, M. F. (1998). ATM associates with and phosphorylates p53: mapping the region of interaction. Nature genetics, 20(4), 398-400. https://doi.org/10.1038/3882

Khosravi, R., Maya, R., Gottlieb, T., Oren, M., Shiloh, Y., \& Shkedy, D. (1999). Rapid ATM-dependent phosphorylation of MDM2 precedes p53 accumulation in response to DNA damage. Proceedings of the National Academy of Sciences of the United States of America, 96(26), 14973-14977. https://doi.org/10.1073/pnas.96.26.14973

Krisnawan, V. E., Stanley, J. A., Schwarz, J. K., \& DeNardo, D. G. (2020). Tumor Microenvironment as a Regulator of Radiation Therapy: New Insights into Stromal-Mediated Radioresistance. Cancers, 12(10), 2916. https://doi.org/10.3390/cancers 12102916

Kunkel, M., Moergel, M., Stockinger, M., Jeong, J. H., Fritz, G., Lehr, H. A., \& Whiteside, T. L. (2007). Overexpression of GLUT-1 is associated with resistance to radiotherapy and adverse prognosis in squamous cell carcinoma of the oral cavity. Oral oncology, 43(8), 796-803. https://doi.org/10.1016/j.oraloncology.2006.10.009

Lee, C. W. \& La Thangue, N. B. (1999). Promoter specificity and stability control of the p53-related protein p73. Oncogene, 18(29), 4171-4181. https://doi.org/10.1038/sj.onc.1202793 
Li, F., Zhou, K., Gao, L., Zhang, B., Li, W., Yan, W., Song, X., Yu, H., Wang, S., Yu, N., \& Jiang, Q. (2016). Radiation induces the generation of cancer stem cells: A novel mechanism for cancer radioresistance. Oncology letters, 12(5), 3059-3065. https://doi.org/10.3892/ol.2016.5124

Liu, Y-P., Zheng, C-C., Huang, Y-N., Xu, W. W, Li, B. (2021). Molecular mechanisms of chemoand radiotherapy resistance and the potential implications for cancer treatment. MedComm, 2(3), 315-340. https://doi.org/10.1002/mco2.55

Mao, Z., Bozzella, M., Seluanov, A., \& Gorbunova, V. (2008). Comparison of nonhomologous end joining and homologous recombination in human cells. DNA repair, 7(10), 1765-1771. https://doi.org/10.1016/j.dnarep.2008.06.018

Marsden, C. G., Dragon, J. A., Wallace, S. S., \& Sweasy, J. B. (2017). Base Excision Repair Variants in Cancer. Methods in enzymology, 591, 119-157. https://doi.org/10.1016/ bs.mie.2017.03.003

Maya, R., Balass, M., Kim, S. T., Shkedy, D., Leal, J. F., Shifman, O., Moas, M., Buschmann, T., Ronai, Z., Shiloh, Y., Kastan, M. B., Katzir, E., \& Oren, M. (2001). ATM-dependent phosphorylation of Mdm2 on serine 395: role in 553 activation by DNA damage. Genes \& development, 15(9), 1067-1077. https://doi.org/10.1101/gad.886901

Meijer, T. W., Kaanders, J. H., Span, P. N., \& Bussink, J. (2012). Targeting hypoxia, HIF1, and tumor glucose metabolism to improve radiotherapy efficacy. Clinical cancer research: anofficialjournalof the American Associationfor CancerResearch, 18(20), 5585-5594. https://doi.org/10.1158/1078-0432.CCR-12-0858

Meng, Y., Beckett, M. A., Liang, H., Mauceri, H. J., van Rooijen, N., Cohen, K. S., \& Weichselbaum, R. R. (2010). Blockade of tumor necrosis factor alpha signaling in tumor-associated macrophages as a radiosensitizing strategy. Cancer research, 70(4), 1534-1543. https://doi.org/10.1158/0008-5472.CAN-09-2995

Mladenov, E., \& Iliakis, G. (2011). Induction and repair of DNA double strand breaks: the increasing spectrum of non-homologous end joining pathways. Mutation research, 711(1-2), 61-72. https://doi.org/10.1016/j.mrfmmm.2011.02.005

Morgan, M. A., \& Lawrence, T. S. (2015). Molecular Pathways: Overcoming Radiation Resistance by Targeting DNA Damage Response Pathways. Clinical cancer research : an official journal of the American Association for Cancer Research, 21(13), 2898-2904. https://doi. org/10.1158/1078-0432.CCR-13-3229

Moureau, S., Luessing, J., Harte, E. C., Voisin, M., \& Lowndes, N. F. (2016). A role for the p53 tumour suppressor in regulating the balance between homologous recombination and non-homologous end joining. Open biology, 6(9), 160225. https://doi.org/10.1098/rsob.160225

Nakashima, R., Goto, Y., Koyasu, S., Kobayashi, M., Morinibu, A., Yoshimura, M., Hiraoka, M., Hammond, E. M., \& Harada, H. (2017). UCHL1-HIF-1 axis-mediated antioxidant property of cancer cells as a therapeutic target for radiosensitization. Scientific reports, 7(1), 6879. https://doi.org/10.1038/s41598-017-06605-1

O'Connell, M. J., Walworth, N. C., \& Carr, A. M. (2000). The G2-phase DNA-damage checkpoint. Trends in cell biology, 10(7), 296-303. https://doi.org/10.1016/s0962-8924(00)01773-6 Olcina, M. M., Grand, R. J., \& Hammond, E. M. (2014). ATM activation in hypoxia - causes and consequences. Molecular \& cellular oncology, 1(1), e29903. https://doi.org/10.4161/ mco. 29903

Patra, K. C., \& Hay, N. (2014). The pentose phosphate pathway and cancer. Trends in biochemical sciences, 39(8), 347-354. https://doi.org/10.1016/j.tibs.2014.06.005

Sharma, A., Singh, K., \& Almasan, A. (2012). Histone H2AX phosphorylation: a marker for DNA damage. Methods in molecular biology (Clifton, N.J.), 920, 613-626. https://doi.org/10.1007/978-1-61779-998-3_40

Shu, K. X., Li, B., \& Wu, L. X. (2007). The p $\overline{53}$ network: 553 and its downstream genes. Colloids and surfaces. B, Biointerfaces, 55(1), 10-18. https://doi.org/10.1016/j.colsurfb.2006.11.003 
Sia, J., Szmyd, R., Hau, E., \& Gee, H. E. (2020). Molecular Mechanisms of Radiation-Induced Cancer Cell Death: A Primer. Frontiers in cell and developmental biology, 8, 41. https://doi.org/10.3389/fcell.2020.00041

Suwa, T., Kobayashi, M., Nam, J. M., Harada H. (2021). Tumor microenvironment and radioresistance. Experimental \& molecular medicine, 53, 1029-1035. https://doi.org/10.1038/ s12276-021-00640-9

Suzuki, K., Mori, I., Nakayama, Y., Miyakoda, M., Kodama, S., \& Watanabe, M. (2001). Radiation-induced senescence-like growth arrest requires TP53 function but not telomere shortening. Radiation research, 155(1 Pt 2), 248-253. https://doi.org/10.1667/0033-7587(2001)155 [0248:rislga]2.0.co;2

Suzuki, K., Yokoyama, S., Waseda, S., Kodama, S., \& Watanabe, M. (2003). Delayed reactivation of p53 in the progeny of cells surviving ionizing radiation. Cancer research, 63(5), 936-941.

Tang, L., Wei, F., Wu, Y., He, Y., Shi, L., Xiong, F., Gong, Z., Guo, C., Li, X., Deng, H., Cao, K., Zhou, M., Xiang, B., Li, X., Li, Y., Li, G., Xiong, W., \& Zeng, Z. (2018). Role of metabolism in cancer cell radioresistance and radiosensitization methods. Journal of experimental \& clinical cancer research : CR, 37(1), 87. https://doi.org/10.1186/s13046-018-0758-7

Tang, Y., He, Y., Shi, L., Yang, L., Wang, J., Lian, Y., Fan, C., Zhang, P., Guo, C., Zhang, S., Gong, Z., Li, X., Xiong, F., Li, X., Li, Y., Li, G., Xiong, W., \& Zeng, Z. (2017). Co-expression of AFAP1-AS1 and PD-1 predicts poor prognosis in nasopharyngeal carcinoma. Oncotarget, 8(24), 39001-39011. https://doi.org/10.18632/oncotarget.16545

Telarovic, I., Wenger, R. H. \& Pruschy, M. (2021). Interfering with Tumor Hypoxia for Radiotherapy Optimization. Journal of experimental \& clinical cancer research : CR, 40 (1), 197. https://doi.org/10.1186/s13046-021-02000-x

Velegzhaninov, I. O., Belykh, E. S., Rasova, E. E., Pylina, Y. I., Shadrin, D. M., \& Klokov, D. Y. (2020). Radioresistance, DNA Damage and DNA Repair in Cells With Moderate Overexpression of RPA1. Frontiers in genetics, 11, 855. https://doi.org/10.3389/fgene.2020.00855

Vitor, A. C., Huertas, P., Legube, G., \& de Almeida, S. F. (2020). Studying DNA DoubleStrand Break Repair: An Ever-Growing Toolbox. Frontiers in molecular biosciences, 7, 24. https://doi.org/10.3389/fmolb.2020.00024

Wang, Y., Gan, G., Wang, B., Wu, J., Cao, Y., Zhu, D., Xu, Y., Wang, X., Han, H., Li, X., Ye, M., Zhao, J., \& Mi, J. (2017). Cancer-associated Fibroblasts Promote Irradiated Cancer Cell Recovery Through Autophagy. EBioMedicine, 17, 45-56. https://doi.org/10.1016/j. ebiom.2017.02.019

Ward, I. M., Wu, X., \& Chen, J. (2001). Threonine 68 of Chk2 is phosphorylated at sites of DNA strand breaks. The Journal of biological chemistry, 276(51), 47755-47758. https://doi.org/10.1074/jbc.C100587200

Xu, B., O'Donnell, A. H., Kim, S. T., \& Kastan, M. B. (2002). Phosphorylation of serine 1387 in Brcal is specifically required for the Atm-mediated S-phase checkpoint after ionizing irradiation. Cancer research, 62(16), 4588-4591.

Yeom, C. J., Goto, Y., Zhu, Y., Hiraoka, M., \& Harada, H. (2012). Microenvironments and cellular characteristics in the micro tumor cords of malignant solid tumors. International journal of molecular sciences, 13(11), 13949-13965. https://doi.org/10.3390/ijms 131113949

Yoshida, G. J., \& Saya, H. (2016). Therapeutic strategies targeting cancer stem cells. Cancer science, 107(1), 5-11. https://doi.org/10.1111/cas.12817

Zhang, H., Luo, H., Jiang, Z., Yue, J., Hou, Q., Xie, R., \& Wu, S. (2016). Fractionated irradiation-induced EMT-like phenotype conferred radioresistance in esophageal squamous cell carcinoma. Journal of radiation research, 57(4), 370-380. https://doi.org/10.1093/jrr/rrw030. 